\title{
1 Distribution and abundance of bottlenose dolphin (Tursiops truncatus) over the French
}

2

\section{Mediterranean continental shelf}

3

4 Hélène Labach ${ }^{1,2}$, Caroline Azzinari ${ }^{3,1}$, Maxime Barbier ${ }^{1}$, Cathy Cesarini ${ }^{4}$, Boris Daniel ${ }^{5}$, Léa 5 David $^{6,1}$, Frank Dhermain ${ }^{7,1}$, Nathalie Di-Méglio ${ }^{6,1}$, Benjamin Guichard ${ }^{5}$, Julie Jourdan ${ }^{7,1}$,

6 Nicolas Robert ${ }^{8}$, Marine Roul $^{6,1}$, Nicolas Tomasi ${ }^{4}$, Olivier Gimenez ${ }^{2,1}$

7

8 (1) GIS3M, Groupement d'Intérêt Scientifique pour les Mammifères marins de Méditerranée, 9 1, avenue Clément Monnier 13960 Sausset-les-Pins, France

10 (2) CEFE, CNRS, Université Montpellier, Université Paul Valéry Montpellier 3, EPHE, IRD,

111919 route de Mende 34090 Montpellier, France

12 (3) BREACH, 11 rue des matins bleus 66300 Ponteilla, France

13 (4) Association Cari Corse, lotissement A Strenna, route du Calvaire 20250 Corte, France

14 (5) Agence française pour la biodiversité, Pôle de Brest, 16 quai de la douane, F29229

15 BREST cedex 2, France

16 (6) EcoOcéan Institut, 18 rue des Hospices 34090 Montpellier, France

17 (7) GECEM, Groupe d'Etude des Cétacés de Méditerranée, 1, avenue Clément Monnier 1813960 Sausset-les-Pins, France

19 (8) Parc naturel régional de Corse, 34 Cours Paoli, 20250 Corte, France 


\section{Abstract}

21 The Mediterranean bottlenose dolphin (Tursiops truncatus) sub-population is listed as 22 vulnerable by the International Union for Conservation of Nature. This species is strictly 23 protected in France and the designation of Special Areas of Conservation (SAC) is required 24 under the European Habitat Directive. However, little information is available about the 25 structure, dynamic and distribution of the population in the French Mediterranean waters. We 26 collected photo-identification data over the whole French Mediterranean continental shelf all 27 year round between 2013 and 2015. We sighted 151 groups of bottlenose dolphins allowing 28 the individually photo-identification of 1,060 animals. The encounter rate distribution showed 29 the presence of bottlenose dolphins over the whole continental shelf all year round. Using 30 capture-recapture methods, we estimated for the first time the size of the bottlenose dolphin 31 resident population at 557 individuals (95\% confidence interval: $216-872$ ) along the French 32 Mediterranean continental coast. Our results were used in support of the designation of a new 33 dedicated SAC in the Gulf of Lion and provide a reference state for the bottlenose dolphin 34 monitoring in the French Mediterranean waters in the context of the Marine Strategy 35 Framework Directive.

\section{Keywords}

38 Abundance, bottlenose dolphin, capture-recapture, distribution, French Mediterranean Sea, 39 photo-identification, Tursiops truncatus 


\section{Introduction}

41 The Common bottlenose dolphin (Tursiops truncatus, Montagu, 1821; hereafter bottlenose 42 dolphin) is considered as a common species in the Mediterranean Sea. It has been observed 43 along most of Mediterranean coast (Bearzi et al. 2009), preferentially over the continental 44 shelf (Di Sciara et al., 1993; Gannier, 2005; Gnone et al., 2011), even though groups have 45 also been observed offshore (Laran et al., 2016). Both resident populations and transient 46 individuals have been reported (Gnone et al., 2011). Mediterranean bottlenose dolphins sup47 population is genetically differentiated from populations inhabiting the contiguous eastern 48 North Atlantic and the Black Sea and is structured into a Western and an Eastern population 49 corresponding to habitat boundaries (Natoli et al. 2005).

50 The bottlenose dolphin Mediterranean sub-population is considered as "vulnerable" on the

51 Red List of the International Union for Conservation of Nature (IUCN). It is listed in Annex II 52 of the Washington Convention on International Trade in Endangered Species, in Appendix II 53 of the Bern Convention for the Conservation of European Wildlife and Natural Habitats, in 54 Appendix II of the Protocol to the Barcelona Convention on Specially Protected Areas of 55 Mediterranean Importance (SPAMI) and is one of the only two species of cetaceans listed in 56 Appendix II of the European Habitats Directive (92/43/CEE). It is also strictly protected in 57 France by the decree of $1^{\text {rst }}$ July 2011 prohibiting, among other things, the destruction, capture 58 and intentional disturbance of marine mammals. In addition, the bottlenose dolphin is the 59 subject of a specific action plan under development by the Agreement on the Conservation of 60 Cetaceans of the Black Sea, Mediterranean Sea and contiguous Atlantic Area (ACCOBAMS).

61 In order to reach legal conservation objectives, the implementation of conservation strategies 62 or action plans for a species requires the assessment of the population conservation status and 63 the identification of trends in the population. Population indicators (e.g., distribution, 
64 abundance) should be regularly evaluated and compared with reference values through

65 standardized long-term monitoring (Cairns et al. 1993; Dale \& Beyeler, 2001).

66 In France, the monitoring program set up for the implementation of the European Marine

67 Strategy Framework Directive (2008/56/EC; MSFD) recommends specific monitoring by

68 photo-identification of resident coastal populations of marine mammal species, including 69 bottlenose dolphins. Photo-identification is a methodology commonly used to monitor 70 bottlenose dolphins (Shane et al., 1986; Defran \& Weller, 1999; Gnone et al., 2011; 71 Karczmarski \& Cockcroft, 2014; Louis et al., 2015) $\square$. Photo-identification allows individual 72 monitoring for inferring population social structure, identifying movements and assessing 73 population dynamics through the estimation of abundance and demographic parameters via 74 capture-recapture (CR) methods (Hammond et al., 2019; Hammond, 2009; Hammond et al., 75 1990; Rosel et al., 2011) $\square$.

76 In French Mediterranean waters, several studies on bottlenose dolphins have been conducted 77 since the 1990s, mainly based on photo-identification (Bompar et al., 1994; Dhermain et al., 78 1999; Labach et al., 2015; Labach et al., 2011; Ripoll et al., 2001), but remain local and 79 punctual. The knowledge of the population's structure, ecology and dynamic remain very 80 poor and unequal.

81 In this study, we conducted the first large-scale survey of bottlenose dolphin based on photo82 identification in the French Mediterranean waters. Standardized photo-identification data 83 were collected all over the French Mediterranean continental shelf in each season over two 84 years through a homogenized protocol by a network of organizations. The objectives of our 85 study were to evaluate the distribution of bottlenose dolphin over the French continental shelf 86 and to provide the first abundance estimate of the resident population.

87

\section{Methods}


90 Study area

91 The French Mediterranean waters present a great diversity and richness of habitats and 92 seabed. The Gulf of Lion, from the Spanish border to Marseille, is a vast continental shelf

93 limited to the north by a sandy and lagoon coastline and to the south by a broad slope cut by 94 numerous canyons. The Corso-Liguro-Provençal basin (Riviera and west coast of Corsica) 95 presents a rocky coastline prolonged by a very narrow continental shelf quickly giving way to 96 an abrupt slope, cut by deep canyons, which debouches on the abyssal plain. To the east of 97 Corsica, the reliefs are shallower with a larger continental shelf. The Corso-Liguro-Provençal 98 basin and the Gulf of Lion are highly productive areas attracting a great diversity of species 99 (D’ortenzio and Ribera Dalcaì, 2009) $\square$.

100 The study area covers the continental shelf of the French Mediterranean waters between the 101 coast and the $500 \mathrm{~m}$ isobath, bounded by the Spanish border to the west, the Italian border to 102 the east, and includes the whole Corsican coastline (Fig 1). The overall study area covers

$10324,481 \mathrm{~km}^{2}$ that was divided in three regions according to their geographic and topographic 104 characteristics: Gulf of Lion $\left(14,731 \mathrm{~km}^{2}\right)$, Riviera $\left(2,866 \mathrm{~km}^{2}\right)$ and Corsica $\left(6,884 \mathrm{~km}^{2}\right)$.

105

\section{Data collection}

107 To ensure a homogeneous sampling over the whole study area, each region was divided in 108 sub-regions of similar area (4 in Gulf of Lion, 2 in Riviera and 3 in Corsica) and assigned to 5 109 local structures involved in marine mammals monitoring (BREACH, CARI, EcoOcean 110 Institut, GECEM and Parc naturel regional de Corse). Each partner conducted 4 days of boat111 based survey in good weather conditions in each season during 2 years in the sub-regions 112 assigned to it. We carried out surveys between summer 2013 and summer 2015 using small 113 sailing and motor boats. We designed these surveys to locate and photo-identify bottlenose 
114 dolphins and optimize the study area's sampling coverage. All partners applied a standard 115 common protocol using a digital application for the data collection specifically designed with 116 Cybertracker (https://www.cybertracker.org/), systematically recording survey tracks with a 117 GPS receiver. When we encountered a group of bottlenose dolphins, we recorded the position 118 of first contact, group size and composition along with group main activity. Whenever 119 possible, we took pictures of both sides of dorsal fins of all individuals of the group with 120 digital reflex camera. We gathered all data and best pictures of each sighting in a common 121 database and uploaded the data on the international web database INTERCET 122 (http://www.intercet.it/).

\section{Photo-identification}

125 We identified individuals using natural marks: scars, nicks, and scratches on their dorsal fins 126 (Würsig and Jefferson, 1990; Würsig and Würsig, 1977) $\square$. We selected best quality pictures 127 (methodology described below in Abundance estimation paragraph) of both profiles of each 128 individual for each sighting and created catalogs of dolphins identified with the history of 129 their sightings. Each partner compared its own catalog with all the others, hence leading to 130 three regional catalogs and one global catalog containing the encounter history of each 131 dolphin photo-identified during the study period.

133 Survey effort

134 We defined the survey effort as the length (in $\mathrm{km}$ ) of track actively traveled prospecting the 135 area with naked eyes by three observers in favorable weather conditions (wind speed lower 136 than Beaufort 3 and good visibility).

138 Group size 
139 We defined a group as all the dolphins seen with naked eyes during the sighting. The

140 estimated group size is the estimated number of individuals observed or photo-identified

141 whenever the latter figure is greater than the estimated one.

142

\section{Distribution}

144 We calculated the encounter rate (ER) as the number of sightings per $\mathrm{km}$ of effort traveled in 145 each region and within each 5'x5' cell of the Marsden grid WGS 84. All maps and spatial 146 analyses were done in R 3.5.0 (R Core Team, 2018) $\square$.

147

\section{Abundance estimation}

149 To estimate the abundance of bottlenose dolphins occurring within the study area, we fitted

150 CR models to the photo-identification data (Hammond et al., 1990) $\square$. We defined a capture

151 as the time an individual was identified with photo-identification, and a recapture as the 152 resighting of an individual already seen during the project.

153 We scored best pictures of each dolphin sighting according to their quality and the 154 distinctiveness of animals using 1 for good, 2 for medium and 3 for bad (Ingram, 2000) $\square$. We 155 used only medium and good quality photos (quality scores =1 or 2) of moderately and well156 marked individuals (distinctiveness score $=1$ or 2 ).

157 Because mortality most likely occurred during the study period, we used the Cormack-Jolly158 Seber (CJS) (Cormack, 1964; Jolly, 1965; Seber, 1965) $\square$ model to estimate abundance while 159 accounting for apparent survival (the product of true survival and fidelity) and a recapture 160 probability less than one. We considered the eight seasons as our capture occasions. The main 161 assumptions underlying the CJS model (Lebreton et al., 1992) are 1) the population is 162 demographically open (i.e. natality and mortality events occur) during the study period; 2) all 163 individuals are correctly identified at each capture occasion and 3) the marks are considered 
164 permanent. Although these assumptions were unlikely to be violated in our study, we formally

165 evaluated the quality of fit the CJS model to the data at hand (see next paragraph).

166 We performed three distinct analyses corresponding to the sightings made in the Gulf of Lion,

167 the Riviera and along the continental coast (Gulf of Lion plus Riviera). We did not pursue CR

168 analyses with the Corsican sightings because of the insufficient number of recaptures (Table

169 1). To fit CR models, we used the RMark package (Laake and Rexstad, 2008) which calls the

170 MARK program (White and Burnham, 1999) in program R. We use the R package R2ucare

171 (Gimenez et al., 2018) to assess the quality of fit of the CJS model to data (Pradel et al.,

172 2005) $\square$. While trap-dependence was not detected, we detected a transient effect that we

173 accounted for by using a two-age class for survival (Roger Pradel et al., 1997). Individuals

174 that were sighted only once were part of the first age-class (transients were included in this

175 class) while all the others were part of the second. The age in CR analysis was considered as

176 the time passed since the animal was first sighted (Madon et al., 2012) $\square$. The proportion of

177 transients was estimated and the abundance estimate amended accordingly (Madon et al.,

178 2012) $\square$. To test and account for the presence of heterogeneity in the detection probability, we

179 used CR mixture models (Pledger et al., 2010) in which animals belong to different classes of

180 detection in proportions to be estimated (Gimenez et al., 2017). For each analysis, we fitted

181 four models incorporating a season and/or heterogeneity in the recapture probability while

182 survival was considered constant over time. To determine the most parsimonious model, the

183 model with the lowest AICc score (Akaike Information Criterion corrected for small sample

184 sizes) (Burnham and Anderson, 2002) was selected (Appendix 1). The selected model was

185 then used in a non-parametric bootstrap procedure (with 500 iterations) to calculate $95 \%$

186 confidence interval for population size (Cubaynes et al., 2010) $\square$.

187 Because we used only well and moderately marked individuals (assumed to be adults) in the $188 \mathrm{CR}$ analyses, the total abundance including poorly marked individuals (juveniles and 
189 neonates) was obtained by correcting the CR-estimated abundance by the proportion of poorly 190 marked individuals (Williams et al., 1993) $\square$.

191

\section{Results}

193 Survey effort

194 We traveled a total of 21,464 $\mathrm{km}$ in survey effort. The distribution of the effort between the 3 195 regions was heterogeneous with a high coverage of Riviera but low coverage of Corsica and 196 the offshore areas of Gulf of Lion. Summer was the best prospected season, autumn and 197 winter being less prospected in the three regions (Fig 2).

198

199 Sightings and photo-identification

200 We sighted 151 groups of bottlenose dolphins during the project. Group size was highly 201 variable in the three regions, mean group size was similar in Riviera and Gulf of Lion and 202 lower in Corsica (Table 1).

203 We made a total of 1,705 photo-identifications of 1,060 dolphins (Table 1), of which 32\% 204 were observed more than once during the project. The percentage of individuals recaptured 205 was higher in Riviera and lower in Corsica. We did not record any recapture between 206 continental and Corsican coast during the project, while we observed 53 individuals in both 207 Riviera and Gulf of Lion.

208

\section{Distribution}

210 We sighted bottlenose dolphins in the whole study area all year round (Fig. 3). Global ER was 211 higher in Corsica and lower in Riviera (Table 1). In Riviera, ER was higher in spring, while in 212 Gulf of Lion and Corsica, ER was higher in summer. 


\section{Abundance estimates}

215 We excluded $15 \%$ of the pictures from the analyses because of their low quality (score 3 ). The 216 percentage of moderate and well-marked individuals was $59 \%$ in Riviera, $77 \%$ in Gulf of 217 Lion and $76 \%$ in the whole continental coast. Many dolphins (68\% in continental coast) were 218 seen only once. The maximum number of captures was 6 for two dolphins (Table 2).

219 According to AICc values (Appendix 1), the model best supported by the three datasets was 220 the model considering two age classes in survival and season-dependent recapture 221 probabilities. The mean ratio of transient animals was estimated to 0.69 (95\% CI $0.36-0.85)$ in 222 Riviera, 0.45 (95\% CI 0.37-0.53) in Gulf of Lion and 0.41 (95\% CI 0.33-0.50) in continental 223 coast.

224 Mean total abundance (corrected by the ratio of moderately and well-marked individuals) of 225 resident population has been estimated at 43 (95\% CI 4-58) individuals in Riviera, 444 (95\% 226 CI 304-555) in Gulf of Lion and 557 (95\% CI 216-872) along the continental coast.

\section{Discussion}

229 Our study provides the first large-scale dedicated photo-identification survey for the 230 bottlenose dolphin in the French Mediterranean waters. We demonstrate the power of a 231 collaborative and coordinated survey to study a mobile species at the scale of a population. 232 Our results show that the whole continental shelf is frequented by bottlenose dolphins, 233 including the entire Gulf of Lion, all year round. We also confirmed the presence of a resident 234 population along the French Mediterranean coasts, for which we provided the first abundance 235 estimate in Riviera and Gulf of Lion.

236 The prospecting effort of $21,464 \mathrm{~km}$ covered $87 \%$ of the study area. We found heterogeneity 237 in this effort between the three regions which we explained by a later start of the survey in 238 Corsica and more difficult survey conditions in the Gulf of Lion because of the important 
239 offshore area which demands long-distance offshore survey trips. The entire coastline of the

240 French Mediterranean is often subject to difficult weather conditions limiting survey effort,

241 especially in Winter.

242 The global encounter rate $(0.007)$ was higher than the encounter rates $(0.0041$ with $\mathrm{CV}=0.17$

243 in winter and 0.0028 with $\mathrm{CV}=0.2$ in summer) obtained with the program "Surveillance 244 Aérienne de la Mégafaune Marine" (SAMM), a comprehensive aerial survey of marine 245 megafauna conducted by the French Biodiversity Agency in 2011 and 2012 over the whole 246 French Exclusive Economic Zone (EEZ), encompassing continental shelf, slope and oceanic 247 waters (Laran et al., 2016) $\square$. The ER in Riviera (0.003) and in Corsica (0.012) was also 248 higher than the maximum ER obtained by (Gnone et al., 2011) $\square$ between 1994 and 2007 in 249 Provence $(E R=0.0006)$ and in Corsica $(E R=0.0086)$, which might be due to an increase in 250 dolphin abundance in these two regions, but the different time scale and different sampling 251 methods make the comparison difficult.

252 The distribution of ER showed that bottlenose dolphins were present over the entire French 253 Mediterranean continental shelf all year round. The higher ER in summer in Gulf of Lion and 254 Corsica was consistent with the results of the SAMM survey, which showed higher ER in 255 winter than in summer in the global EEZ, but a distribution more important in offshore waters 256 in winter and in coastal waters of Gulf of Lion and Corsica in summer (Laran et al., 2016) $\square$. 257 These results, together with the detection of a strong transient effect in the CR analyses, 258 suggest a seasonal migration of bottlenose dolphins between offshore waters in winter to 259 coastal waters in summer, especially in Gulf of Lion and Corsica. The sighting of 53 dolphins 260 both in Riviera and Gulf of Lion also points towards eastward and westward movements. No 261 movement between the continental areas and Corsica was observed during the project, 262 although 5 individuals were identified both in Corsica and along continental coast in previous 263 studies (Gnone et al., 2011). The identification of distinct units and the characterization of 
264 connections between them is the object of ongoing work using population genetic and social 265 structure analyses based on photo-identification and biopsy data collected during the present 266 study. The higher percentage of badly marked individuals (41\%) suggests, in Riviera, a higher 267 percentage of immature dolphins than in Gulf of Lion (23\%).

268 The robust estimation of abundance relies on the validation of CR model assumptions. The 269 two-year sampling period and the fact that newborns were observed in the study area suggest 270 that assumption 1 of the CJS model is likely to have been respected. Assumptions 2 and 3 are 271 ensured by the fact that only moderately and well-marked individuals with good-quality 272 photographs were included in the analysis. Also, if the marks evolve, the short sampling 273 period would allow to recognize the animals.

274 The average total population along the continental coast between 2013 and 2015 estimated at 275557 (95\% CI 216-872) individuals was higher than the estimates of the only previous census 276 campaign dedicated to bottlenose dolphins in the same area, which estimated by observed 277 count (ignoring imperfect detection), the number of bottlenose dolphins between 200 and 209 278 in the Gulf of Lion and 16 in Provence (Ripoll et al., 2001) $\square$. These figures are not 279 inconsistent with our abundance estimates which were corrected to account for imperfect 280 detection. Our abundance estimates are coherent with the results obtained from the program 281 SAMM with the distance sampling methodology, which estimated the absolute abundance of 282 bottlenose dolphins in French territorial water (within 12 miles of the coast) at 350 (95\% CI 283 150-900) dolphins inside the Pelagos Sanctuary and 500 (95\% CI 115-2,500) outside in 284 Winter and at 1,800 (95\% CI 900-3,500) individuals inside the Pelagos Sanctuary and 450 285 (95\% CI 120-1,700) outside in Summer (Laran et al., 2016) $\square$.

\section{6}

\section{Implications for conservation}

288 Our study provides an operational framework as well as a reference state for the 289 implementation of a long-term large-scale monitoring of the resident bottlenose dolphin 
290 population in the French Mediterranean waters in the framework of the Marine Strategy 291 Framework Directive. We shared the data on the international webGIS platform INTERCET 292 (http://www.intercet.it/) which will allow to enlarge the study of this species beyond French 293 boundaries to the basin and Mediterranean scale.

294 The results of our study together with those from the SAMM survey (Laran et al., 2016) $\square$ led 295 to an update of the Mediterranean bottlenose conservation status in the national IUCN Red 296 List which was changed from "vulnerable" in 2009 to "nearly threatened" in 2017 because of 297 knowledge improvement. Our demonstration of the presence of bottlenose dolphins in the 298 entire Gulf of Lion led France to submit the designation of a dedicated offshore SAC 299 encompassing the whole Gulf of Lion continental shelf beyond the territorial waters and to the 300 recognition of this area as an important marine mammal area (IMMA) for bottlenose dolphins 301 (https://www.marinemammalhabitat.org/imma-eatlas/). Our results will also contribute to 302 update the ACCOBAMS bottlenose dolphin conservation plan.

303 We recommend that the photo-identification monitoring of bottlenose dolphins over the 304 French Mediterranean continental shelf is continued in the long term to allow the 305 identification of trends in the population and the implementation of adaptive management of 306 the species at the sub-regional scale. 


\section{Acknowledgements}

308 We acknowledge MAVA Foundation, the French Biodiversity Agency and the Pelagos

309 Sanctuary, who financially supported the GDEGeM project and also thank Fondation de

310 France for funding through the INTERACT project. We thank all the partners for their

311 involvement in the data collection: BREACH, CARI Corse, EcoOcéan Institut, GECEM and

312 Parc naturel régional de Corse as well as all the people who participated to the survey. We

313 also acknowledge Guido Gnone and Michela Bellingeri for their support in the use of the

314 INTERCET platform. 


\section{Tables}

316

317 Table 1: Sightings and photo-identification of bottlenose dolphins

\begin{tabular}{|c|c|c|c|c|c|c|c|c|c|}
\hline & Sightings & ER & $\begin{array}{c}\text { Group size } \\
\text { (SD) }\end{array}$ & $\begin{array}{c}\text { Right } \\
\text { profiles p }\end{array}$ & $\begin{array}{l}\text { Left } \\
\text { rofiles }\end{array}$ & Captures & Recaptures & $\begin{array}{l}\text { Identified } \\
\text { individuals }\end{array}$ & $\begin{array}{l}\text { Recaptured } \\
\text { individuals }\end{array}$ \\
\hline Corsica & 41 & 0.012 & $5.3(4.5)$ & 140 & 130 & 167 & $35(21 \%)$ & 132 & $26(20 \%)$ \\
\hline Riviera & 18 & 0.003 & $15.7(10.3)$ & 227 & 207 & 260 & $113(43 \%)$ & 147 & $45(31 \%)$ \\
\hline Gulf of & & & & & & & & 834 & $+248(30 \%)$ \\
\hline Lion & 92 & 0.007 & $16.6(13.2)$ & 920 & 895 & 1278 & $446(35 \%)$ & & \\
\hline Global & 151 & 0.007 & $13.6(12.5)$ & 1287 & 1,232 & 1705 & $648(38 \%)$ & 1060 & $334(32 \%)$ \\
\hline
\end{tabular}

318

319 Number of sightings, encounter rates (ER), mean group size and standard deviation (SD),

320 number of right and left profiles pictures, number of captures and number and percentage of

321 recaptures, number of individuals identified, number and percentage of individuals captured

322 more than once.

323

324 Table 2. Distribution of individuals per number of captures.

\begin{tabular}{cccccccc}
\hline & 1 & 2 & 3 & 4 & 5 & 6 & Total \\
\hline Riviera & 79 & 9 & 5 & 3 & 1 & 0 & 97 \\
Gulf of Lion & 411 & 100 & 51 & 15 & 1 & 2 & 580 \\
Continental coast & 458 & 123 & 61 & 21 & 6 & 2 & 671 \\
\hline
\end{tabular}

325

326 Number of dolphins identified 1, 2, 3, etc. times in each dataset. 
328 Tableau 3: Abundance estimates $(\mathrm{N})$ and $95 \%$ confidence intervals in Riviera, Gulf of Lion 329 and Continental coast in each season. For Winter and Summer 2014 in Riviera, the recapture 330 probabilities were estimated very low, which impeded the estimation of abundance.

331

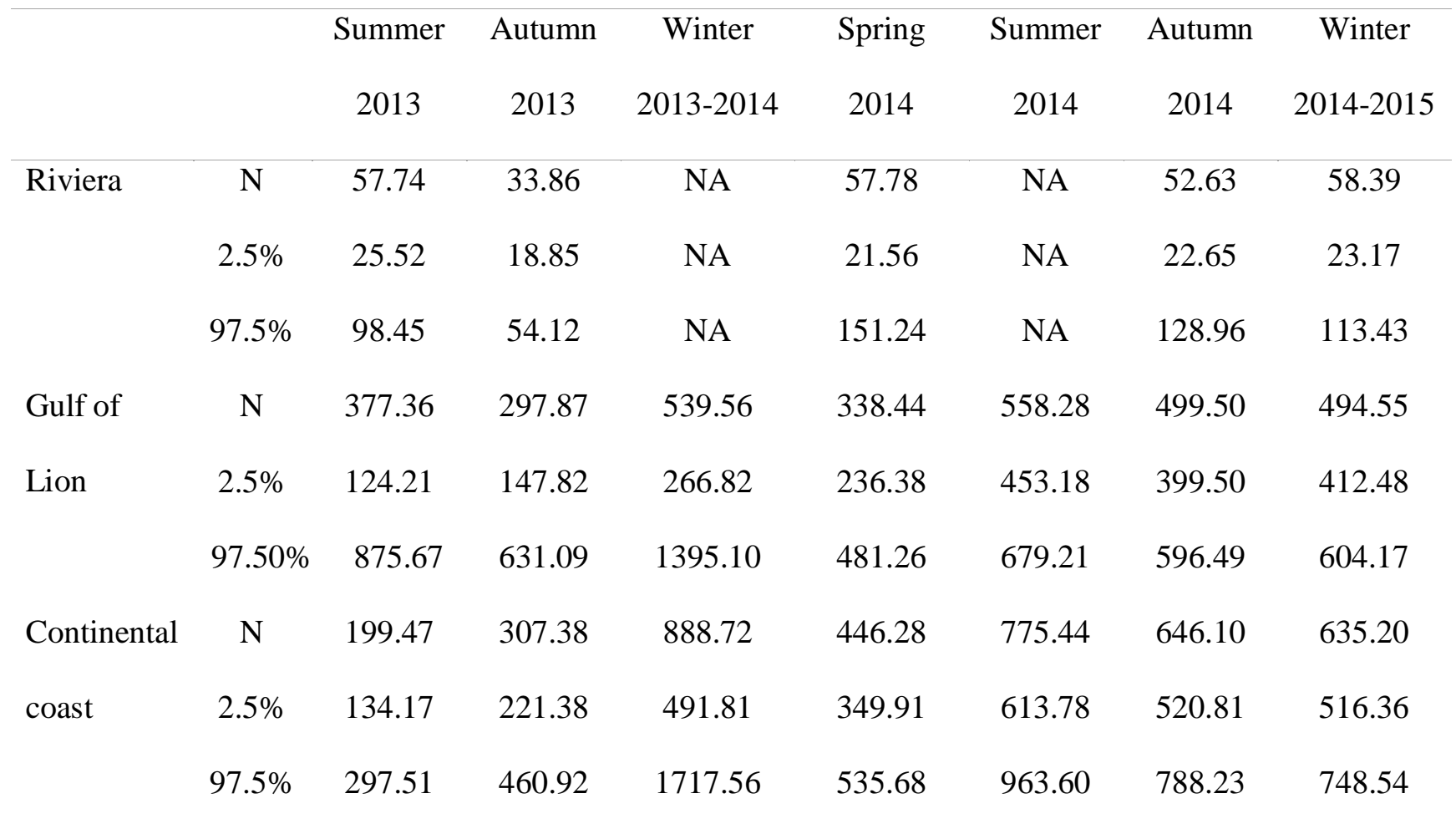




\section{Figure legends}

334

335 Figure 1: Study area (in blue) encompassing the French Mediterranean continental shelf in 336 north-western Mediterranean Sea. The bathymetry is also displayed on the map.

338 Figure 2: Seasonal distribution of survey effort (number of kilometers actively traveled per 339 5'x5' cell) between 2013 and 2015 over the French Mediterranean continental shelf.

340

341 Figure 3: Seasonal distribution of bottlenose dolphins over French Mediterranean waters

342 between 2013 and 2015. Encounter rates (number of sightings/km) per 5'x5' cell. 
343 Bibliography

344 Bearzi, G., Fortuna, C. M., \& Reeves, R. R. (2009). Ecology and conservation of common

345 bottlenose dolphins (Tursiops truncatus) in the Mediterranean Sea. Mammal Review,

346 39(2), 92-123. https://doi.org/10.1111/j.1365-2907.2008.00133.

347 Bompar, J., Baril, D., Dhermain, F., \& Ripoll, T. (1994). Estimation of the Corsican

348 population of bottlenose dolphins (Tursiops truncatus): is there a real conflict with

349 fishermen. European Research on Cetacean, 92-94.

350 Burnham, K. P., \& Anderson, D. R. (2002). Model Selection and Multimodel Inference: A

$351 \quad$ Practical Information-Theoretic Approach (Springer Berlin, ed.).

352 Cairns, J., Mccormick, P. V, \& Niederlehner, B. R. (1993). A Proposed Framework for

353 Developing Indicators of Ecosystem Health for the Great Lakes Region A proposed

354 framework for developing indicators of ecosystem health. Hydrobiologia, 263.

355 https://doi.org/10.1007/BF00006084.

356 Cormack, R. M. (1964). Estimates of Survival from the Sighting of Marked Animals.

357 Biometrika, 51(3/4), 429. https://doi.org/10.2307/2334149.

358 Cubaynes, S., Pradel, R., Choquet, R., Duchamp, C., Gaillard, J.-M., Lebreton, J.-D., et al.

359 (2010). Importance of Accounting for Detection Heterogeneity When Estimating

360 Abundance: the Case of French Wolves. Conservation Biology, 24(2), 621-626.

361 https://doi.org/10.1111/j.1523-1739.2009.01431.

362 D'ortenzio, F., \& Ribera Dalcaì, M. (2009). On the trophic regimes of the Mediterranean Sea:

363 a satellite analysis. In Biogeosciences (Vol. 6). Retrieved from

$364 \quad$ www.biogeosciences.net/6/139/2009/. 
365 Dale, V. H., \& Beyeler, S. C. (2001). Challenges in the development and use of ecological

366 indicators. Ecological Indicators, 1(1), 3-10. https://doi.org/10.1016/S1470-

$367 \quad 160 X(01) 00003-6$.

368 Defran, R. H., \& Weller, D. W. (1999). Occurrence, distribution, site fidelity, and school size 369 of bottlenose dolphins (Tursiops truncatus) off San Diego, California. Marine Mammal $370 \quad$ Science, 15(2), 366-380. https://doi.org/10.1111/j.1748-7692.1999.tb00807.

371 Dhermain, F., Ripoll, T., Bompar, J., David, L., \& Di-meglio, N. (1999). First evidence of the 372 movement of a bottlenose dolphin (Tursiops truncatus) between Corsica and Hyères 373 archipelago, south $\square$ eastern France. European Research on Cetaceans, 306-311.

374 Di Sciara, G. N., Venturino, M. C., Zanardelli, M., Bearzi, G., Borsani, F. J., \& Cavalloni, B.

375 (1993). Cetaceans in the central Mediterranean Sea: Distribution and sighting

376 frequencies. Bolletino Di Zoologia, 60(1), 131-138.

377 https://doi.org/10.1080/11250009309355800.

378 Gannier, A. (2005). Summer distribution and relative abundance of delphinids in the 379 Mediterranean Sea. Revue d'Ecologie (La Terre et La Vie), 60(3), 223-238.

380 Gimenez, O., Cam, E., \& Gaillard, J. (2017). Individual heterogeneity and capture-recapture $381 \quad$ models $\square$ : what, why and how $\square$ ? Oikos, 127(5), 664-686.

382 https://doi.org/10.1111/oik.04532.

383 Gimenez, O., Lebreton, J. D., Choquet, R., \& Pradel, R. (2018). R2ucare: An r package to 384 perform goodness-of-fit tests for capture-recapture models. Methods in Ecology and 385 Evolution, 9(7), 1749-1754. https://doi.org/10.1111/2041-210X.13014.

386 Gnone, G., Bellingeri, M., Dhermain, F., Dupraz, F., Nuti, S., Bedocchi, D., et al. (2011). 
387 Distribution, abundance, and movements of the bottlenose dolphin (Tursiops truncatus)

388 in the Pelagos Sanctuary MPA (north-west Mediterranean Sea). Aquatic Conservation:

389 Marine and Freshwater Ecosystems, 21(4), 372-388. https://doi.org/10.1002/aqc.1191.

390 Hammond, P. S., Mizroch, S., \& Donovan, G. P. (2019). Report of the workshop on

391 individual recognition and the estimation of cetacean population parameters. 12, 3-17.

392 Hammond, P. S. (2009). Mark-Recapture. Encyclopedia of Marine Mammals, 705-709.

393 https://doi.org/10.1016/B978-0-12-373553-9.00163-2.

394 Hammond, P. S., Mizroch, S., \& Donovan, G. P. (1990). Use of Photo-Identification and

395 Other Techniques to Estimate Population Parameters. Report of the International

$396 \quad$ Whaling Commission Special Issue 12 Cambridge 1990. (12), 448.

397 Jolly, G. M. (1965). Explicit Estimates from Capture-Recapture Data with Both Death and

398 Immigration-Stochastic Model. Biometrika, 52(1/2), 225.

399 https://doi.org/10.2307/2333826.

400 Karczmarski, L., \& Cockcroft, V. (2014). Matrix photo-identification technique applied in

401 studies of free-ranging bottlenose and humpback dolphins. Aquatics Mammals, 24.3,

402 143-162. https://www.researchgate.net/publication/232524538.

403 Laake, J., \& Rexstad, E. (2008). RMark - an alternative approach to building linear model in $404 \operatorname{MARK}$ (E. Cooch and G. C. White, eds.).

405 Labach, H., Dhermain, F., \& Dupraz, F. (2015). Suivi de la population de grands dauphins

406 Tursiops truncatus le long des côtes provençales (Méditerranée nord-occidentale ).

407 Scientific Reports of Port-Cros National Park, 272, 267-272. 
408 Labach, H., Dhermain, F., Dupraz, F., \& Colombey, M. (2011). Suivi des Grands Dauphins

409 (Tursiops truncatus) et Dauphins de Risso (Grampus griseus) sur le secteur des îles d'

410 Hyères en 2009. Scientific Reports of Port-Cros National Park, 162, 143-162.

411 Laran, S., Pettex, E., Authier, M., Blanck, A., David, L., Dorémus, G., et al. (2016). Seasonal

412 distribution and abundance of cetaceans within French waters- Part I: The North-Western

413 Mediterranean, including the Pelagos sanctuary. Deep Sea Research Part II: Topical

414 Studies in Oceanography, (xxxx), 1-11. https://doi.org/10.1016/j.dsr2.2016.12.011.

415 Lebreton, J.-D., Burnham, K. P., Clobert, J., \& Anderson, D. R. (1992). Modeling Survival 416 and Testing Biological Hypotheses Using Marked Animals: A Unified Approach with 417 Case Studies. Ecological Monographs, 62(1), 67-118. https://doi.org/10.2307/2937171.

418 Louis, M., Gally, F., Barbraud, C., Béesau, J., Tixier, P., Simon-bouhet, B., et al. (2015).

419 Social structure and abundance of coastal bottlenose dolphins, Tursiops truncatus, in the

420 Normano-Breton Gulf, English Channel. Journal of Mammalogy, 96(x), 1-13.

421 https://doi.org/10.1093/jmamma/gyv053.

422 Madon, B., Garrigue, C., Pradel, R., \& Gimenez, O. (2012). Transience in the humpback

423 whale population of New Caledonia and implications for abundance estimation. Marine

424 Mammal Science, 29(4), n/a-n/a. https://doi.org/10.1111/j.1748-7692.2012.00610.

425 Natoli, A., Birkun, A., Aguilar, A., Lopez, A., \& Hoelzel, A. R. (2005). Habitat structure and 426 the dispersal of male and female bottlenose dolphins (Tursiops truncatus). Proceedings 427 of the Royal Society B: Biological Sciences, 272(1569), 1217-1226.

428 https://doi.org/10.1098/rspb.2005.3076.

429 Pledger, S., Pollock, K. H., \& Norris, J. L. (2010). Open Capture-Recapture Models with 
430 Heterogeneity: II. Jolly-Seber Model. Biometrics, 66(3), 883-890.

431 https://doi.org/10.1111/j.1541-0420.2009.01361.

432 Pradel, R., Giménez, O., \& Lebreton, J.-D. (2005). Principles and interest of GOF tests for

433 multistate capture-recapture models. Animal Biodiversity and Conservation, 28(2), 189-

434 204. https://doi.org/56772.

435 Pradel, Roger, Hines, J. E., Lebreton, J.-D., \& Nichols, J. D. (1997). Capture-Recapture

436 Survival Models Taking Account of Transients. Biometrics, 53(1), 60.

437 https://doi.org/10.2307/2533097.

438 Ripoll, T., Dhermain, F., Baril, D., Roussel, E., David, L., \& Beaubrun, P. (2001). First

439 summer population estimate of bottlenose dolphins along the north $\square$ western coasts of

440 the occidental Mediterranean basin. European Research on Cetaceans, 393-396.

441 Rosel, P. E., Mullin, K. D., Garrison L., Schwacke, L., Adams, J., Balmer, B., Conn, P. B., et

442 al. (2011). Photo-identification Capture-Mark-Recapture Techniques for Estimating

443 Abundance of bay, Sound and Estuary Populations of Bottlenose Dolphins along the

444 U.S. East Coast and Gulf of Mexico: A Workshop Report. Journal of Heredity,

$445 \quad$ (January), 30.

446 Seber, G. A. F. (1965). A Note on the Multiple-Recapture Census. Biometrika, 52(1/2), 249.

$447 \quad$ https://doi.org/10.2307/2333827.

448 Shane, S. H., Wells, R. S., Würsig, B., \& Odell, D. K. (1986). Ecology, behavior and social 449 organization of the bottlenose dolphin: a review. Marine Mammal Science, 2(1), 34-63.

450 https://doi.org/10.1111/j.1748-7692.1986.tb00026.

451 White, G. C., \& Burnham, K. P. (1999). Program MARK: survival estimation from 
452 populations of marked animals. Bird Study, 46(sup1), S120-S139.

453 https://doi.org/10.1080/00063659909477239.

454 Williams, J. A., Dawson, S. M., \& Slooten, E. (1993). The abundance and distribution of

455 bottlenosed dolphins ( Tursiops truncatus ) in Doubtful Sound, New Zealand. Canadian

456 Journal of Zoology, 71(10), 2080-2088. https://doi.org/10.1139/z93-293.

457 Würsig, B., \& Jefferson, T. a. (1990). Methods of photo-identification for small cetaceans.

458 Report of the International Whaling Commission, pp. 43-52.

459 Würsig, B., \& Würsig, M. (1977). The Photographic Determination of Group Size,

460 Composition, and Stability of Coastal Porpoises (Tursiops truncatus). Science,

$461 \quad$ 198(4318), 755-756. https://doi.org/10.1126/science.198.4318.755. 
462 Appendix 1

463

464 Table of AICc values

465

Model* number of $\quad$ QAICc Deviance chat parameters

\begin{tabular}{llllll}
\hline Gulf of Lion & 1 & 9 & 983.89 & 126.80 & 1.39 \\
& 2 & 3 & 1002.54 & 157.67 & 1.39 \\
& 3 & 11 & 987.54 & 126.38 & 1.39 \\
& 4 & 5 & 1006.58 & 157.67 & 1.39 \\
Riviera & 1 & 9 & 211.15 & 68.91 & 0.87 \\
& 2 & 3 & 254.54 & 125.70 & 0.87 \\
& 3 & 11 & 214.72 & 67.82 & 0.87 \\
& 4 & 5 & 258.83 & 125.70 & 0.87 \\
Continental coast & 1 & 9 & 1130.85 & 129.72 & 1.60 \\
& 2 & 3 & 1154.71 & 165.75 & 1.60 \\
& 3 & 11 & 1132.26 & 127.03 & 1.60 \\
& 4 & 5 & 1156.45 & 163.45 & 1.60
\end{tabular}

$466 *$ Models were built as follows:

467 Model 1 considers two age classes in survival and season-dependent recapture probabilities

468 Model 2 considers two age classes in survival and constant recapture probabilities

469 Model 3 considers two age classes in survival, heterogeneous and season-dependent

470 recapture probabilities

471 Model 4 considers two age classes in survival and heterogeneous recapture probabilities

472 


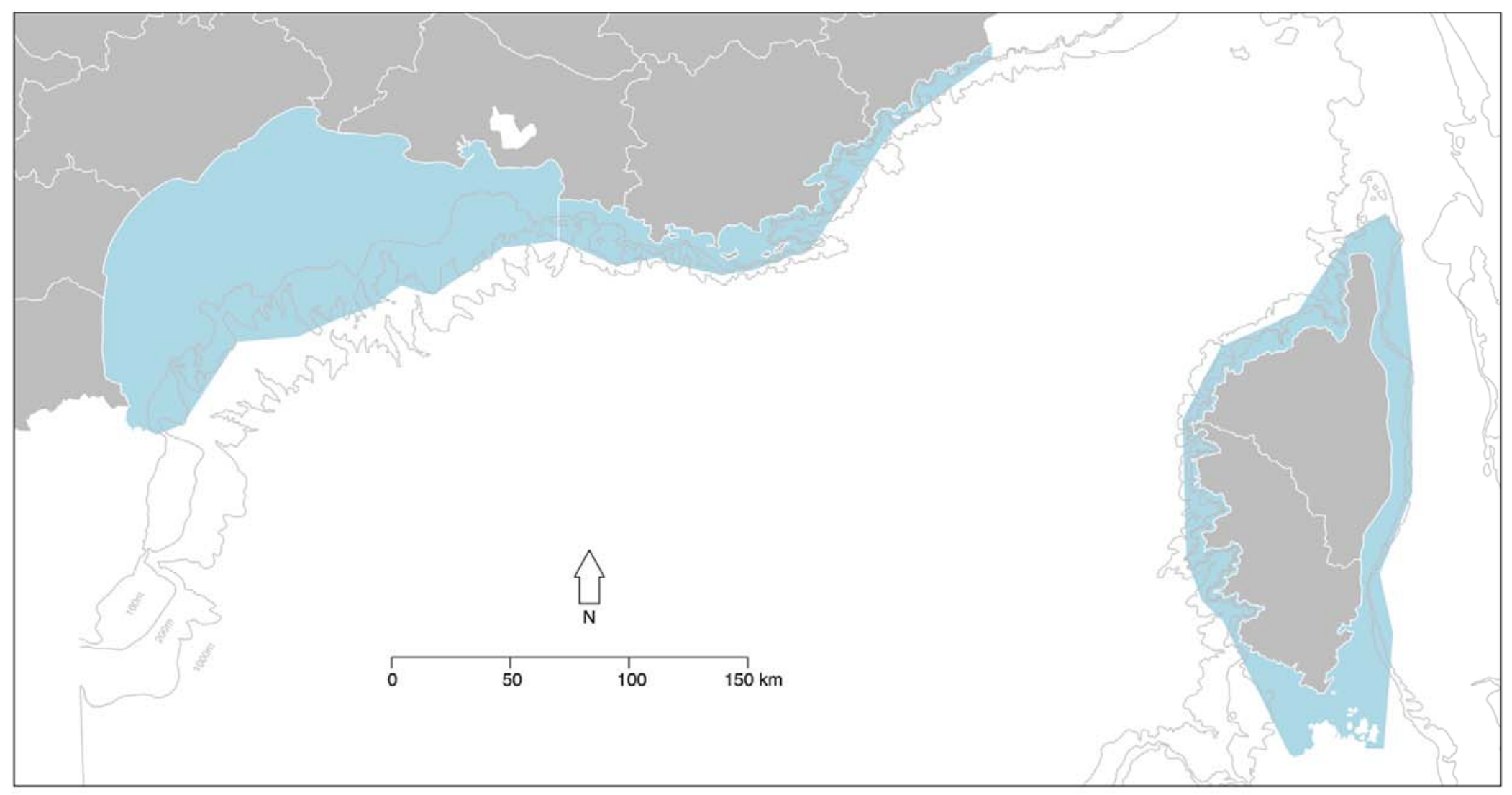

473

Figure 1

474 


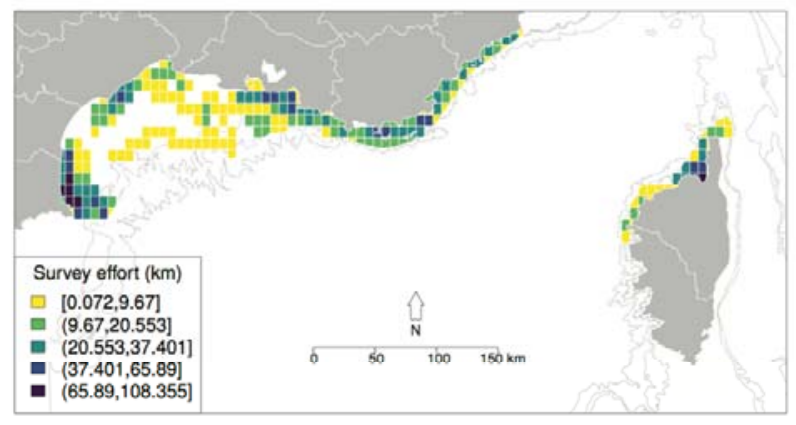

(a) Autumn

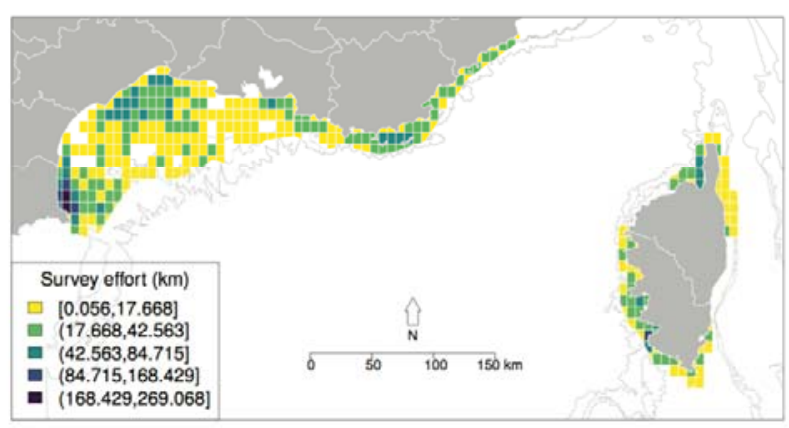

(c) Summer

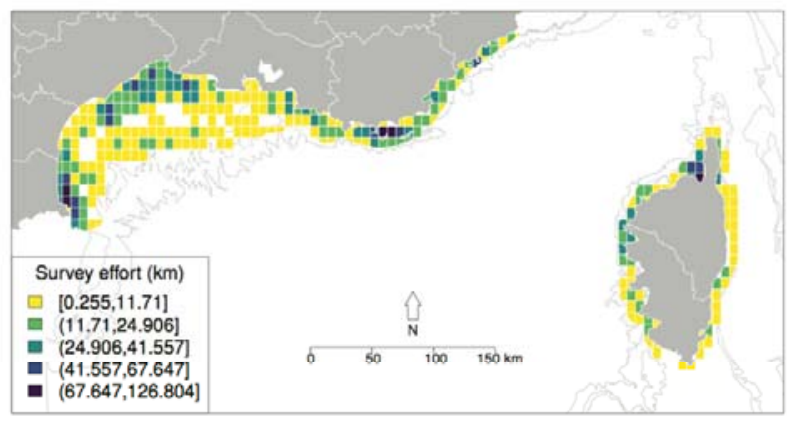

(b) Spring

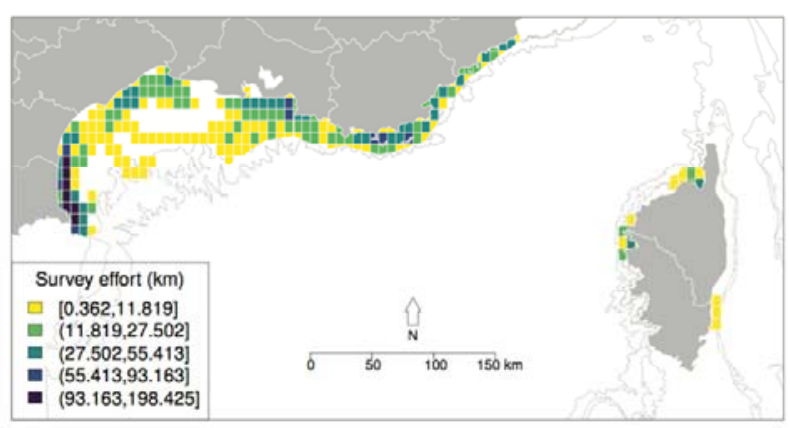

(d) Winter 


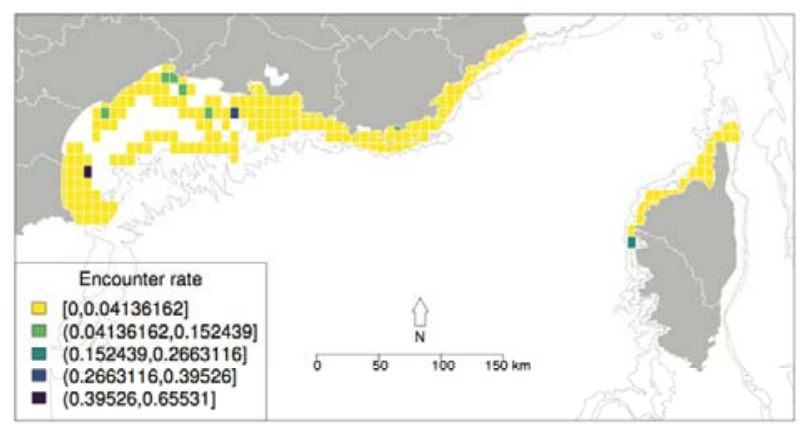

(a) Autumn

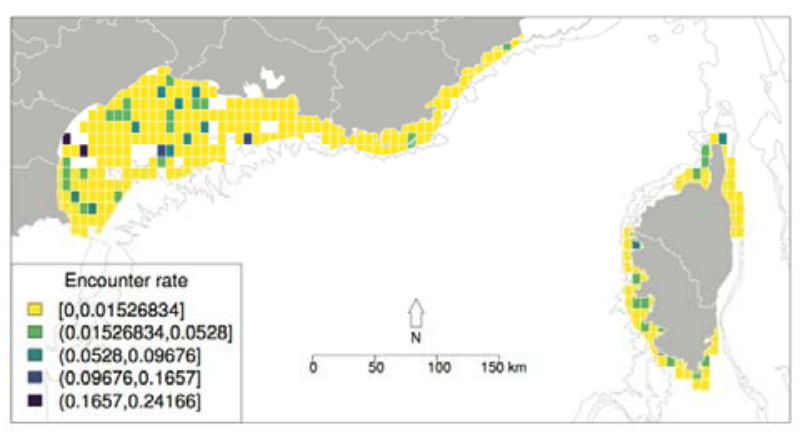

(c) Summer

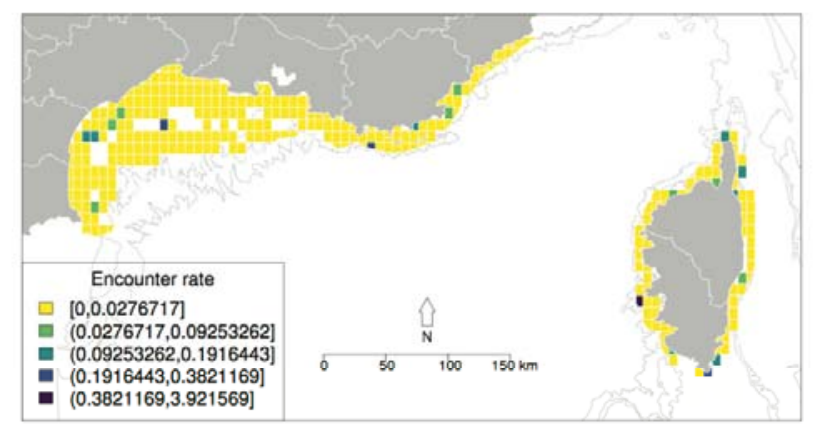

(b) Spring

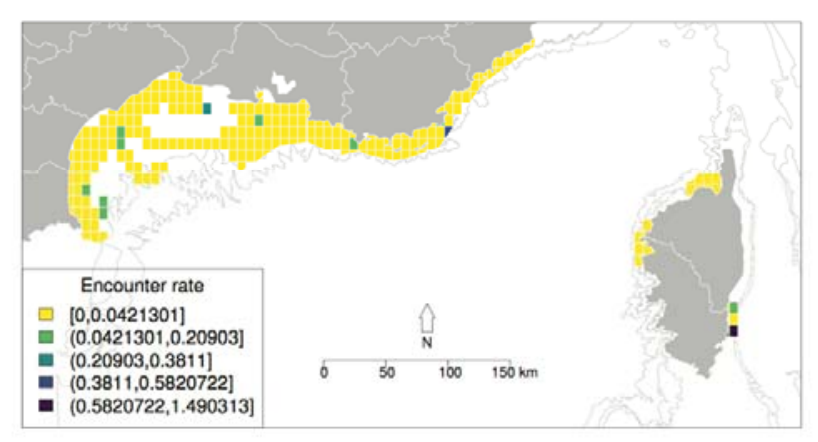

(d) Winter

477

\section{Figure 3}

